\title{
Microcapsule induced toughening in a self-healing polymer composite
}

\author{
E. N. BROWN \\ Department of Theoretical and Applied Mechanics and the Beckman Institute for Advanced \\ Science and Technology, University of Illinois at Urbana-Champaign, Urbana, IL 61801, \\ USA; Los Alamos National Laboratory, MS-E544, Los Alamos, NM 87545, USA \\ E-mail: en_brown@lanl.gov \\ S. R. WHITE \\ Department of Aerospace Engineering and the Beckman Institute for Advanced Science \\ and Technology, University of Illinois at Urbana-Champaign, 306 Talbot Laboratory, \\ 104 S. Wright St., Urbana, IL 61801, USA \\ E-mail: swhite@uiuc.edu
}

N. R. SOTTOS

Department of Theoretical and Applied Mechanics and the Beckman Institute for Advanced Science and Technology, University of Illinois at Urbana-Champaign, 216 Talbot Laboratory, 104 S. Wright St., Urbana, IL 61801, USA

E-mail:n-sottos@uiuc.edu

Microencapsulated dicyclopentadiene (DCPD) healing agent and Grubbs' Ru catalyst are incorporated into an epoxy matrix to produce a polymer composite capable of self-healing. The fracture toughness and healing efficiency of this composite are measured using a tapered double-cantilever beam (TDCB) specimen. Both the virgin and healed fracture toughness depend strongly on the size and concentration of microcapsules added to the epoxy. Fracture of the neat epoxy is brittle, exhibiting a mirror fracture surface. Addition of DCPD-filled urea-formaldehyde (UF) microcapsules yields up to $127 \%$ increase in fracture toughness and induces a change in the fracture plane morphology to hackle markings. The fracture toughness of epoxy with embedded microcapsules is much greater than epoxy samples with similar concentrations of silica microspheres or solid UF polymer particles. The increased toughening associated with fluid-filled microcapsules is attributed to increased hackle markings as well as subsurface microcracking not observed for solid particle fillers. Overall the embedded microcapsules provide two independent effects: the increase in virgin fracture toughness from general toughening and the ability to self-heal the virgin fracture event. (c) 2004 Kluwer Academic Publishers

\section{Introduction}

A novel approach to recover the fracture properties of thermosetting polymers has been introduced by White et al. [1]. Healing is achieved by incorporating a microencapsulated healing agent and a catalytic chemical trigger within a polymer matrix. A propagating crack ruptures the microcapsules and exposes catalyst particles. Crack opening draws the healing agent into the crack plane, where contact with the catalyst phase initiates polymerization. The polymerized healing agent reestablishes structural integrity across the crack plane.

Conclusive demonstration of self-healing was obtained with a healing agent based on the ring-opening metathesis polymerization (ROMP) reaction [1]. Dicyclopentadiene (DCPD), a highly stable monomer with excellent shelf life, was encapsulated in ureaformaldehyde (UF) microcapsules. A small volume fraction of microcapsules was dispersed in an epoxy matrix along with Grubbs' transition metal catalyst [2]. This self-healing epoxy was able to recover over $90 \%$ of its virgin fracture toughness [3]. In addition to providing an efficient mechanism for self-healing, the presence of DCPD-filled UF microcapsules also significantly increased the inherent fracture toughness of the epoxy.

In the present work, we investigate toughening mechanisms induced by embedded microcapsules in a selfhealing epoxy and the corresponding effect on healing efficiency. Several investigations of microcapsulefilled polymers have appeared in the literature using alternate terms such as hollow spheres [4], cenospheres [5], microballons [6, 7], hollow particles [8, 9], hollow microspheres [8, 10], and bubbles [11]. Most of the literature examines the behavior of glass (rather than polymer) microcapsules, with mixed conclusions regarding the effect on fracture behavior. Azimi et al. [4] 
found a $126 \%$ increase in fracture toughness for epoxy (DGEBA cured with piperadine) with the addition of 10 vol\% of glass microcapsules. Similarly, a $185 \%$ increase in toughness was measured for polyester filled with 27 vol\% silane coated glass microcapsules [5]. In contrast, Zihlif and Ragosta [6] reported a 33\% reduction of toughness under impact loading with the addition of 10 vol\% glass microcapsules in epoxy (DGEBA cured with a polyamide). El-Hadek and Tippur [7] also found a $20 \%$ reduction of toughness for epoxy and urethane filled with 10 vol\% glass microcapsules. Fewer investigations of polymer microcapsules have appeared in the literature, but all have consistently reported increases in fracture toughness. Begheri and Pearson [8] added latex and acrylic microcapsules to epoxy (DGEBA cured with aminoethyl piperazine) and found fracture toughness increased by $141 \%$ for $10 \mathrm{vol} \% \mathrm{mi}$ crocapsules. Toughening by sub $15 \mu \mathrm{m}$ diameter microcapsules was attributed to shear yielding at the crack tip, while a combination of shear yielding and microcracking was identified as the operative mechanism at larger diameters. Jung [12] also measured significant toughening with the addition of epoxide-filled polyoxymethylene urea (PMU) microcapsules to a DCPD polyester matrix.

Although the mechanisms are not well understood, results of these previous investigations combined with recent observations in self-healing polymers indicate that polymer microcapsules significantly toughen a brittle polymer matrix. In the current work, we seek to elucidate the specific toughening mechanisms associated with the addition of polymer microcapsules through extensive fracture testing, examination of fracture surfaces and comparison with other types of particle reinforcement.

\section{Experimental procedure}

\subsection{Fracture tests and fractography}

The fracture behavior of microcapsule-filled epoxy was investigated using a tapered double-cantilever beam (TDCB) test. Side grooves ensured controlled crack growth along the centerline of the brittle specimen. The TDCB fracture geometry, developed by Mostovoy et al. [13], provided a crack-length-independent measure of fracture toughness,

$$
K_{\mathrm{IC}}=\alpha P_{\mathrm{C}},
$$

which only required measurement of the critical fracture load $P_{\mathrm{C}}$ and knowledge of the geometric term $\alpha$. For the TDCB sample geometry in Fig. $1, \alpha=11.2 \times$ $10^{3} \mathrm{~m}^{-3 / 2}$ was determined experimentally as discussed by Brown et al. [3].

Healing efficiency was assessed using the protocol established by White et al. [1]. TDCB fracture specimens were pin loaded and tested under displacement control, at $5 \mu \mathrm{m} / \mathrm{s}$ displacement rate. Samples were tested to failure, measuring compliance and peak load to establish the initial (virgin) fracture toughness. Load was then removed while allowing the crack faces to come back in contact. Brown et al. [3] showed the development of healed fracture toughness within $25 \mathrm{~min}$

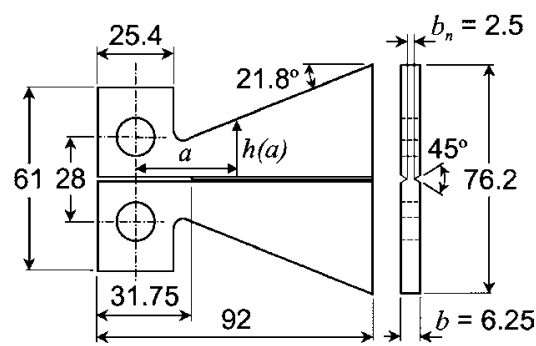

Figure 1 Tappered double-cantilever beam (TDCB) geometry [3]. Note: all dimensions in $\mathrm{mm}$.

of virgin fracture, which closely corresponds to the gelation time of the polyDCPD [14]. Maximum healing efficiency was reached within $10 \mathrm{~h}$, and samples were retested after $24 \mathrm{~h}$ to determine the healed fracture toughness. Crack healing efficiency, $\eta$, was defined as the ability to recover fracture toughness [15]. For the TDCB geometry, the healing efficiency was calculated simply as the ratio of critical fracture loads for the healed and virgin samples,

$$
\eta=\frac{K_{\mathrm{IC}_{\text {healed }}}}{K_{\mathrm{IC}_{\text {virgin }}}}=\frac{P_{\mathrm{C}_{\text {healed }}}}{P_{\mathrm{C}_{\text {virgin }}}} .
$$

Fracture surface morphologies were examined with a Philips XL30 ESEM-FEG. After fracture, specimens were mounted and sputtered with gold/palladium. Micrographs were obtained using $10 \mathrm{kV}$ secondary electrons in high vacuum mode. Cross sections of the fracture plane and subsurface features were further examined by a cryofracture technique [16]. Samples were immersed in liquid nitrogen for approximately one hour, then immediately fractured with a razor blade perpendicular to the original fracture plane and viewed in the ESEM.

\subsection{Materials and sample preparation}

Urea-formaldehyde microcapsules containing DCPD monomer (Fig. 2) were manufactured with average diameters of 50,180, and $460 \mu \mathrm{m}$ using the emulsion in situ polymerization microencapsulation method outlined by Brown et al. [17]. Shell wall thickness was $190 \pm 30 \mathrm{~nm}$ for all batches. Tapered double-cantilever

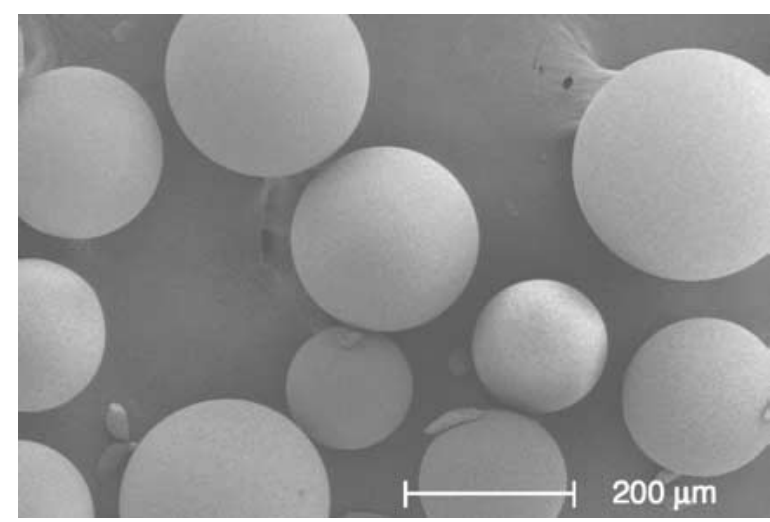

Figure 2 Urea-formaldehyde microcapsules containing DCPD prepared by emulsion in situ microencapsulation [17] 
TABLE I Properties of the constituents

\begin{tabular}{|c|c|c|c|}
\hline Properties & Epoxy & $\begin{array}{l}\text { Urea- } \\
\text { formaldehyde } \\
\text { microcapsules }\end{array}$ & $\begin{array}{l}\text { Silica } \\
\text { microspheres }\end{array}$ \\
\hline Density $\left(\mathrm{kg} / \mathrm{m}^{3}\right)$ & 1160 & $\sim 1000$ & 2510 \\
\hline Diameter $(\mu \mathrm{m})$ & - & $\begin{array}{r}50 \pm 20 \\
180 \pm 40 \\
460 \pm 80\end{array}$ & $70 \pm 12$ \\
\hline Wall thickness (nm) & - & $190 \pm 30$ & - \\
\hline$K_{\mathrm{Ic}}\left(\mathrm{MPa} \mathrm{m}^{1 / 2}\right)$ & $0.55 \pm 0.04$ & - & - \\
\hline Young's modulus (GPa) & $3.4 \pm 0.1$ & - & - \\
\hline $\begin{array}{l}\text { Ultimate stress } \\
\text { strength }(\mathrm{MPa})\end{array}$ & $39 \pm 4$ & - & - \\
\hline
\end{tabular}

TABLE II Mechanical properties of neat epoxy and epoxy with embedded microcapsules

\begin{tabular}{llll}
\hline $\begin{array}{l}\text { Microcapsule } \\
\text { concentration (vol\%) }\end{array}$ & $\begin{array}{l}\text { Diameter } \\
(\mu \mathrm{m})\end{array}$ & $\begin{array}{l}\text { Young's } \\
\text { modulus }(\mathrm{GPa})\end{array}$ & $\begin{array}{l}\text { Ultimate } \\
\text { stress }(\mathrm{MPa})\end{array}$ \\
\hline 0 & - & $3.4 \pm 0.1$ & $39 \pm 4$ \\
6 & $50 \pm 20$ & $3.2 \pm 0.1$ & $22 \pm 5$ \\
6 & $180 \pm 40$ & $3.2 \pm 0.1$ & $24 \pm 3$ \\
11 & $180 \pm 40$ & $3.1 \pm 0.2$ & $20 \pm 4$ \\
17 & $180 \pm 40$ & $2.8 \pm 0.1$ & $20 \pm 2$ \\
22 & $180 \pm 40$ & $2.7 \pm 0.1$ & $18 \pm 2$ \\
28 & $180 \pm 40$ & $2.6 \pm 0.1$ & $14 \pm 1$ \\
33 & $180 \pm 40$ & $2.4 \pm 0.1$ & $14 \pm 2$ \\
\hline
\end{tabular}

beam specimens were cast from $\mathrm{EPON}^{\circledR} 828$ epoxy resin (DGEBA) and 12 pph Ancamine ${ }^{\circledR}$ DETA (diethylenetriamine) curing agent with a prescribed concentration of microcapsules and $2.5 \mathrm{wt} \%$ catalyst (for self-healing samples) mixed into the resin. The epoxy mixture was degassed, poured into a closed silicone rubber mold and cured for $24 \mathrm{~h}$ at room temperature, followed by $24 \mathrm{~h}$ at $30^{\circ} \mathrm{C}$. A razor blade was gently tapped into a molded starter notch to generate a sharp precrack. Relevant physical and mechanical properties are listed in Tables I and II. The modulus and ultimate strength both decrease with increasing microcapsule content, these trends being similar to other microcapsule $[4,6-10,12]$ and rubber $[4,8]$ modified systems.

Other types of epoxy TDCB samples were also fabricated for comparison of fracture mechanisms. Two different types of solid fillers, silica microspheres and UF particles, and two types of "voids" were investigated. Solid silica microspheres (McMaster-Carr) of $\sim 70 \mu \mathrm{m}$ average diameter were washed in acetone and baked at $100^{\circ} \mathrm{C}$ prior to their use in epoxy. For some sample batches the microspheres were treated with a coupling agent ( 1 pph of Dow z-6040 silane added to the resin) to improve adhesion. UF particles approximately $180 \mu \mathrm{m}$ in diameter were created by repetitive deposition during emulsion in situ polymerization and added to epoxy samples. Voids were introduced into another batch of samples by aggressive mixing of the resin before filling the mold. Void content was determined by optical measurement of the void area fraction on the fracture surface. Samples with poorly bonded microcapsules were obtained by coating UF microcapsules with release agent (Buehler 20-8185-016 and Miller Stephenson MS-122DF).

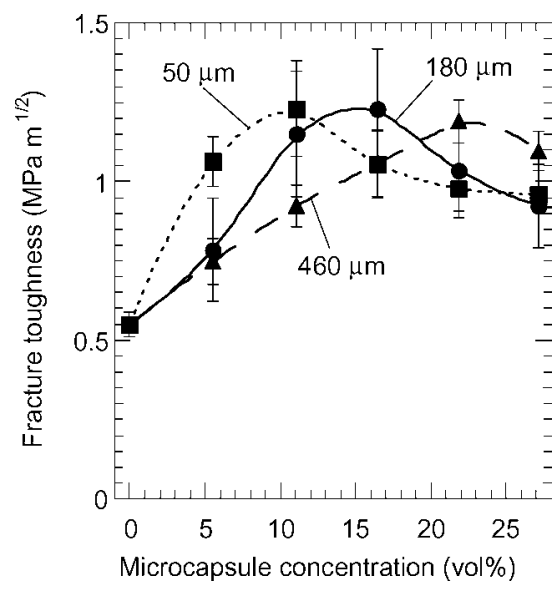

Figure 3 Influence of microcapsule concentration and diameter on fracture toughness.

\section{Fracture and self-healing behavior}

Virgin fracture toughness is plotted in Fig. 3 as a function of microcapsule concentration for three different microcapsule diameters. Fracture toughness increases with microcapsule concentration until reaching a roughly equivalent peak value for all three capsule sizes. As the microcapsule concentration increases further, the fracture toughness decreases. The average maximum toughness is $127 \%$ greater than for neat epoxy ( $0 \%$ microcapsules). The concentration of microcapsules at which the maximum value occurs depends strongly on microcapsule diameter. Smaller microcapsules exhibit maximum toughening at lower concentration.

The healed fracture toughness and healing efficiency are plotted in Fig. 4 for the 50 and $180 \mu \mathrm{m}$ diameter microcapsule specimens. Healed fracture toughness (Fig. 4a) increases steadily with microcapsule concentration until reaching a plateau at about $20 \mathrm{vol} \%$ for both cases. Similar to White et al. [1], when the healing efficiency $\eta$ is calculated relative to the fracture toughness of neat epoxy (no microcapsules or catalyst) a value greater than $100 \%$ is achieved. The healing efficiency (Fig. 4b) calculated via Equation 2 depends more significantly on capsule diameter. The maximum healing efficiency for $180 \mu \mathrm{m}$ microcapsules occurs at low concentrations $(\sim 5 \mathrm{vol} \%)$ just prior to the peak virgin fracture toughness (Fig. 3). For $50 \mu \mathrm{m}$ microcapsules, high healing efficiency only occurs at higher microcapsule concentrations ( $\sim 20 \mathrm{vol} \%)$ since more capsules are required to deliver the same volume of DCPD healing agent to the fracture plane. In both cases, over 70\% recovery of virgin fracture toughness is obtained through careful selection of microcapsule concentration.

\section{Fracture toughness comparisons}

For the range of sizes and concentrations investigated, samples with embedded microcapsules have consistently higher fracture toughness than neat epoxy. Similar, but not nearly as significant toughening has been measured for particulate fillers such as solid silica microspheres [e.g., 18, 19]. The microcapsules in this study consist of a thin $190 \pm 30 \mathrm{~nm}$ shell wall surrounding a liquid core, yet their behavior in situ is 


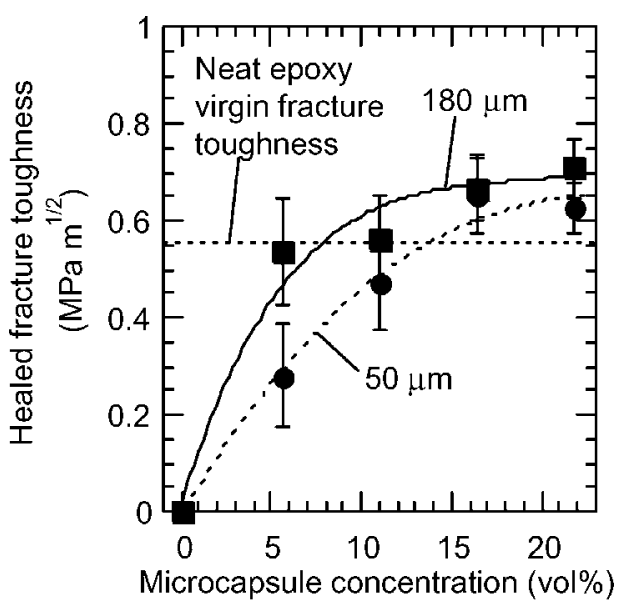

(a)

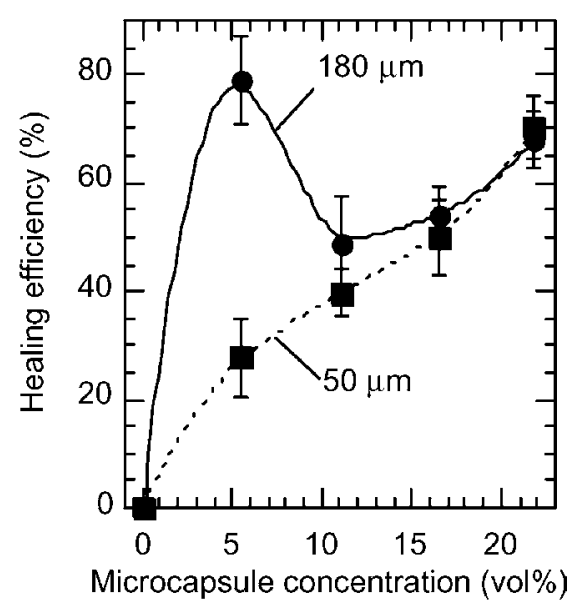

(b)

Figure 4 Influence of microcapsule concentration on self-healing behavior: (a) Healed fracture toughness and (b) healing efficiency as a function of concentration for 50 and $180 \mu \mathrm{m}$ diameter microcapsules, measured $24 \mathrm{~h}$ after virgin fracture.

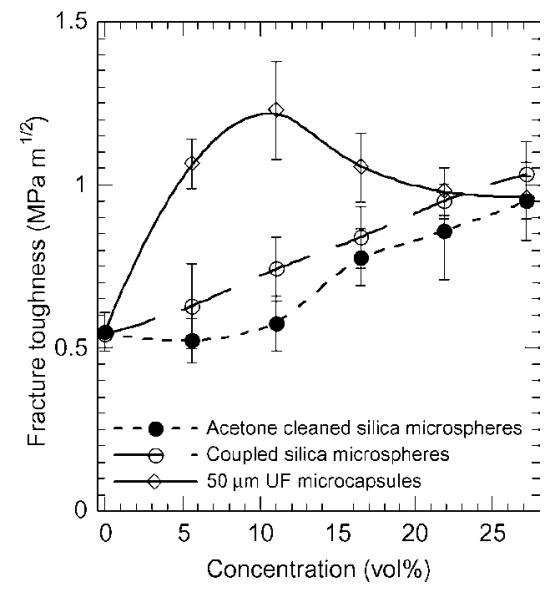

Figure 5 Fracture toughness of samples with solid silica microspheres compared to UF microcapsules as a function of concentration.

more reflective of solid particles than voids. Previous investigations of polymers with voids report a reduction in fracture toughness with increasing void concentration [7]. In this section, the fracture behavior of epoxy with embedded microcapsules is compared to the same epoxy incorporating solid silica microspheres, UF particles, voids, or poorly bonded microcapsules.

Fracture toughness for samples with 0 to $27 \mathrm{vol} \%$ of $70 \pm 12 \mu \mathrm{m}$ silica microspheres is plotted in Fig. 5 . Below 10 vol\%, untreated silica microspheres provide little or no increase in fracture toughness from the neat resin. Above 10 vol\%, the fracture toughness increases suddenly and then grows modestly with microsphere concentration. In contrast, fracture toughness increases continuously with concentration for microspheres treated with coupling agent to promote adhesion and appears to scale linearly with volume fraction. Addition of 27 vol\% coupling agent treated silica microspheres yields a maximum $87 \%$ increase in toughness. In comparison, UF microcapsules induce greater toughening $(127 \%)$ at a much lower concentration (11 vol\%). Moreover, since silica microspheres are 2.5 times more dense than the UF microcapsules, microcapsule toughening is achieved at a greatly reduced overall weight.

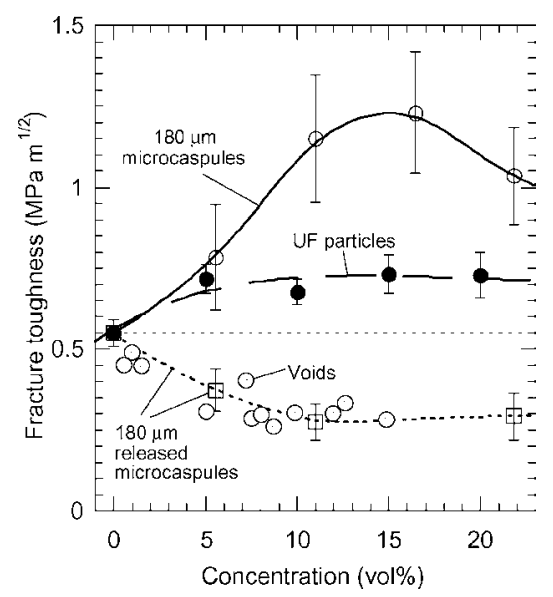

Figure 6 Comparison of fracture toughness of samples with wellbonded UF microcapsules, UF particles, voids and UF microcapsules treated with release agent.

The influence of embedded UF particles on fracture toughness is shown in Fig. 6. The addition of a small volume ( $5 \mathrm{vol} \%$ ) of UF particles provides a $36 \%$ increase in toughness, but no further increase in toughness is observed at higher concentrations. Toughening due to the addition of solid UF particles is much less significant than toughening induced by liquid-filled UF microcapsules.

Fig. 6 illustrates the relative effects of void content and poor microcapsule bonding on epoxy fracture toughness. In both cases, toughness decreases with increasing concentrations until reaching a plateau at $\sim 10 \mathrm{vol} \%$. Microcapsules treated with release agent are easily pulled from cured epoxy and debond rather than rupture. Hence, well-bonded microcapsules induce different fracture mechanisms than voids or solid particles. To further clarify the operative toughening mechanisms, the fracture surfaces of the various sample types were examined by ESEM.

\section{Fracture mechanisms}

\subsection{Neat epoxy}

Fracture surfaces of neat epoxy samples contain three distinct zones. As shown in Fig. 7a, a $37 \mu \mathrm{m}$ thick 


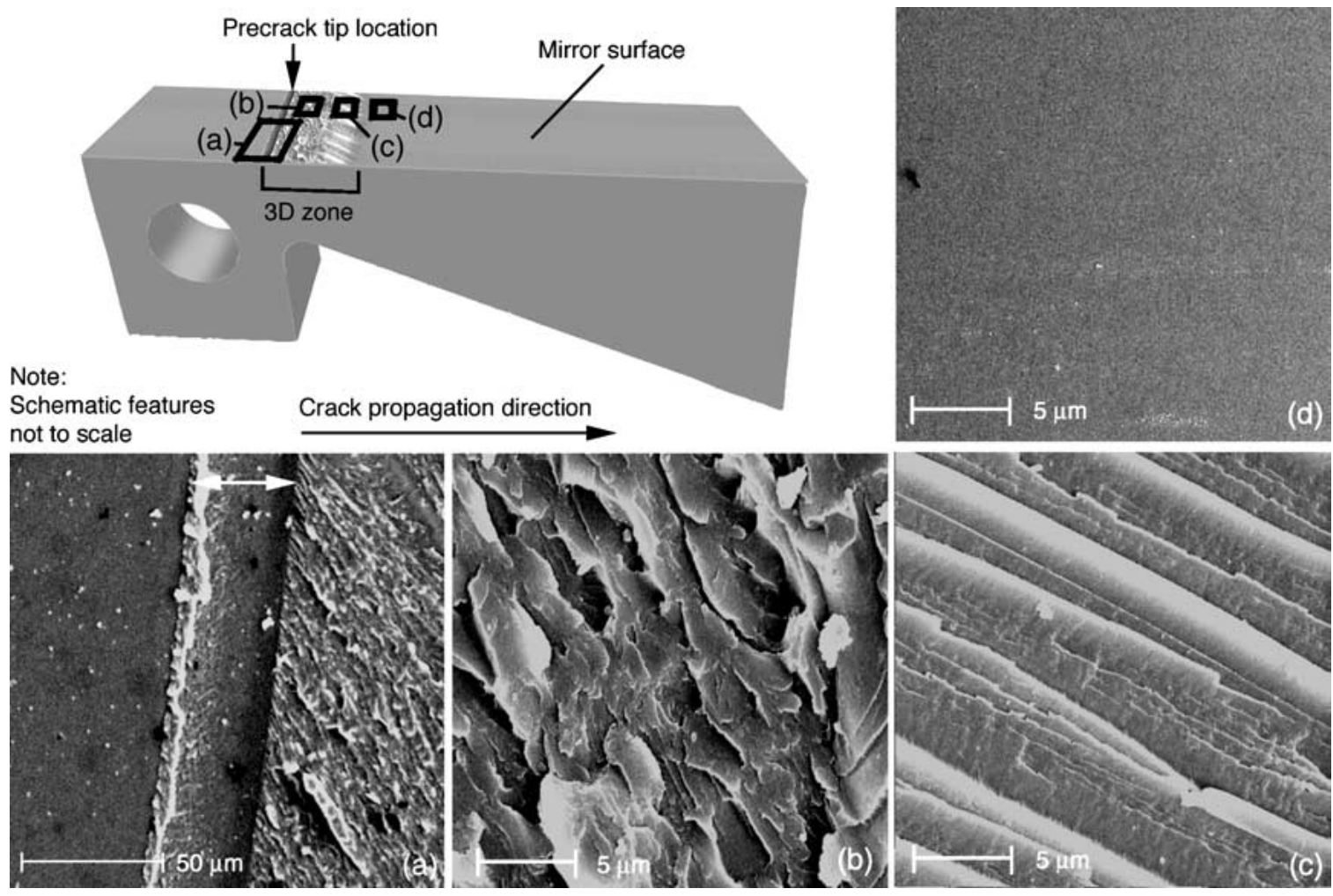

Figure 7 Scanning electron micrographs of fracture plane in neat epoxy: (a) Precrack tip location and $37.5 \mu \mathrm{m}$ plastic zone denoted by arrow, (b) hackle markings following plastic zone, and (c) transition zone from hackle marking to mirror fracture surface, and (d) Mirror surface of brittle fracture plane extending the length of the specimen. Note: The crack propagation is from left to right in all images.

plastic zone is present at the location of the precrack tip. The size of this region is consistent with theoretical estimates of the plastic zone using Irwin's theory [20]. The surface of the fracture plane just before the plastic zone is smooth and mirror like, typical of cleavage-like brittle fracture [21]. Immediately beyond the plastic zone, a series of hackle markings are present (Fig. 7b). Hackle marking is a feather-like fracture morphology resulting from small-scale secondary crack formation parallel to the fracture plane [21]. Within $1.5 \mathrm{~mm}$ of the plastic zone the hackle markings transition into striations in the direction of crack propagation (Fig. 7c). Complete transition back to a mirror fracture surface occurs within $2.0 \mathrm{~mm}$ as shown in Fig. 7d. The size of the hackle marking zone coincides roughly with the size of the threedimensional (3D) stress zone $(\sim 2.2 \mathrm{~mm})$ as proposed by Rosakis and Ravi-Chandar [22]. Wallner lines, reported to arise from the interaction of the fracture field with associated acoustic waves [23], are present in the mirror zone of a limited number of samples.

\subsection{Epoxy with embedded microcapsules}

Three changes in fracture mechanism from that of neat epoxy are evident on fracture planes with embedded microcapsules. The plastic zone identified for neat epoxy is no longer present as a distinct band (Fig. 8a). Instead, there is a direct transition to hackle markings as shown in Fig. 8b. Tails originating from broken microcapsules in the fracture plane (Fig. 8c) indicate a crack pinning toughening mechanism may be operative. Crack pinning typically occurs in polymers with well-bonded, high stiffness particles, such as silica [19]. In the case of embedded microcapsules, hackle markings become the dominant fracture plane morphology. Hackle markings are present over the entire crack plane (Fig. 8d) with the degree of roughness largest near the precrack tip.

\subsection{Tail structures}

Tails in the wake of microcapsules form a step surface as shown in Fig. 9a. Discontinuity of the crack front in the presence of a microcapsule allows out-of-plane divergence of the crack surface on either side of the microcapsule. In order to regain continuity beyond the microcapsule, the two crack faces reconnect by formation of a step. In contrast, crack pinning by solid silica microspheres leads to the formation of a delta tail as shown in Fig. 9b. Their formation is postulated to be the result of a multistage process of crack propagation [24]. Silica microspheres first locally arrest crack growth. When sufficient energy is applied, the crack progresses along the interface of the inclusion. Tails form during snap-through when the crack front rapidly advances. The delta tail represents the lowest energy crack path. While the step tails may indicate a crack blunting process and an associated toughening mechanism, tails in the wake of microcapsules do not correspond to the classic crack pinning mechanism associated with rigid particles. Fracture planes containing UF particles contain no tails. The crack propagates through the equator of the UF particles rather than along the interface, as in the case of silica microspheres.

\subsection{Hackle structure}

The hackle patterns on the fracture surface of the microcapsule filled epoxy were further investigated using 

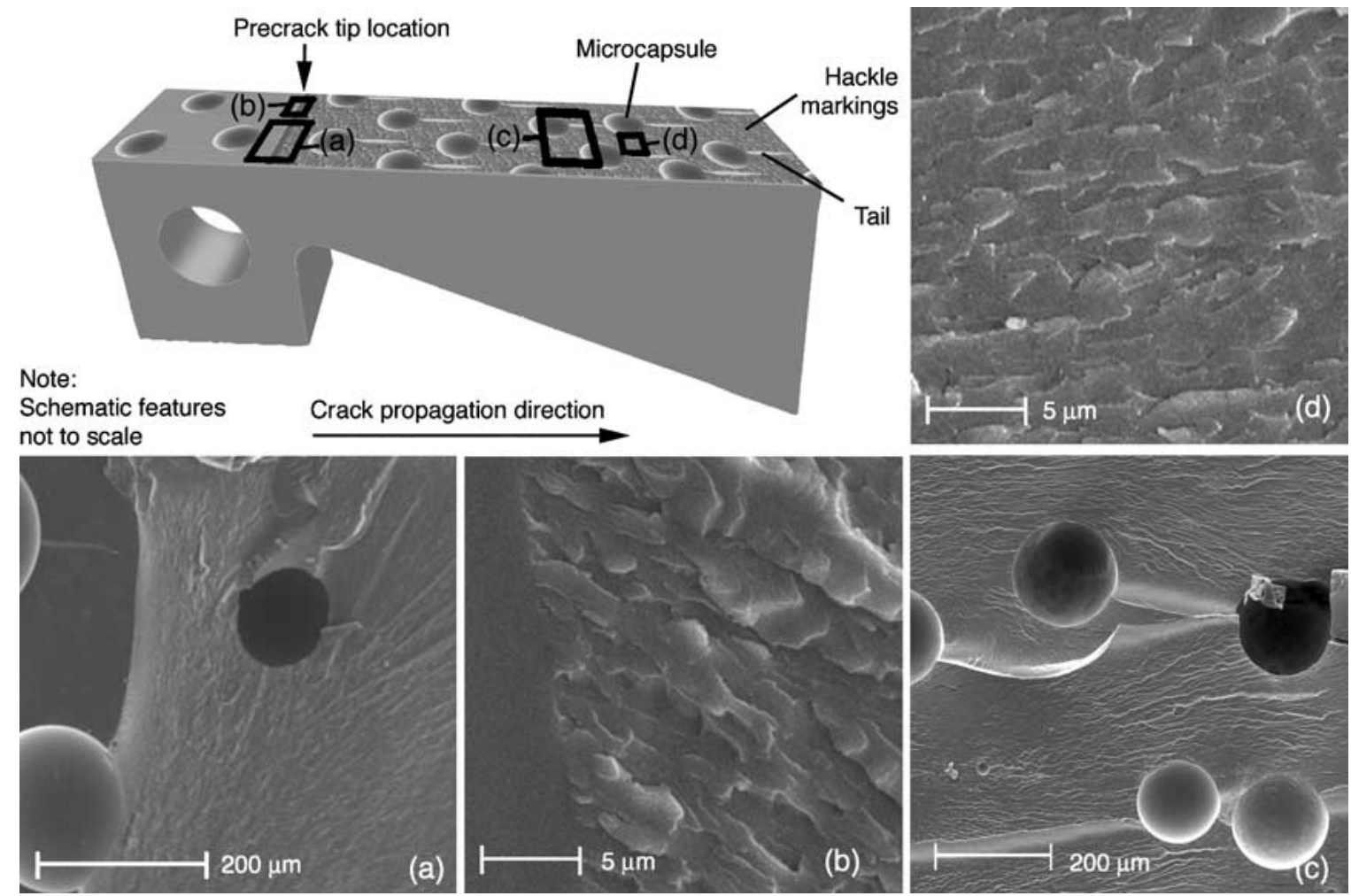

Figure 8 Scanning electron micrographs of fracture plane in epoxy with $11 \mathrm{vol} \% 180 \mu \mathrm{m}$ UF microcapsules: (a) precrack tip in the presence of microcapsules lacking a defined plastic zone (b) (c) tails in the wake of microcapsules and (d) hackle marking presence $30 \mathrm{~mm}$ from precrack tip. Note: The crack propagation is from left to right in all images.
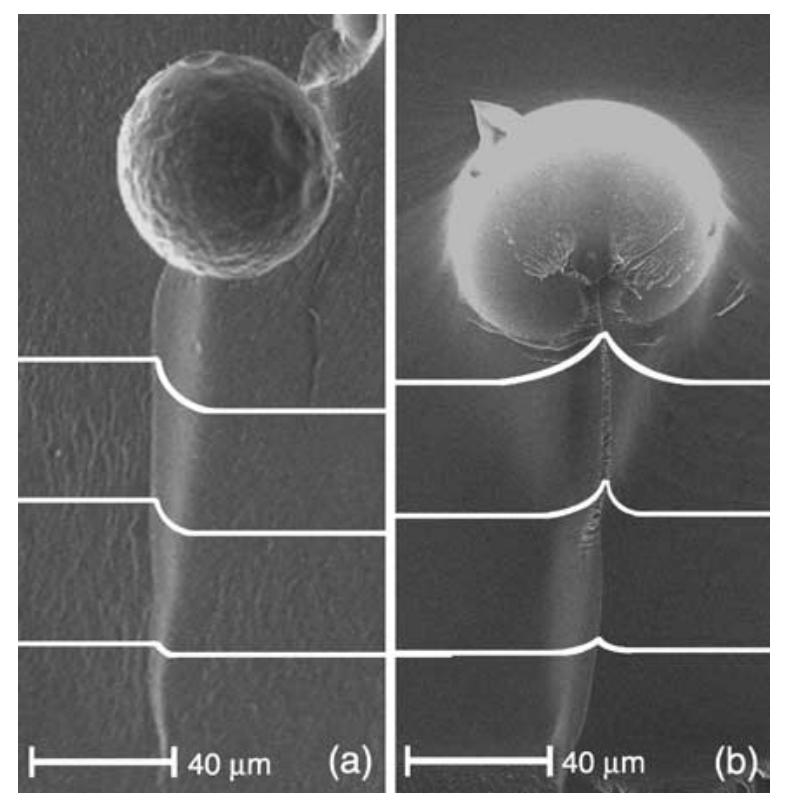

Figure 9 Scanning electron micrographs of tail structures: (a) Step tail in wake of microcapsule and (b) delta tail in wake of silica microsphere. Note: The crack propagation direction is from top to bottom in both images.

a cryofracture technique. The penetrating hackle structure was viewed from two perpendicular directions in the cross section, shown schematically in Fig. 10. In the view perpendicular to the crack propagation direction (Fig. 10a) finger-like extensions appear lifted from the fracture surface, indicating sub-surface damage. Cross sectional views opposite to the crack propagation direction (in Fig. 10b and c) reveal small cracks penetrating below the primary fracture plane. Additionally, microcracking is present beneath the fracture plane (Fig. 10d). The presence of secondary cracks in the hackle zone [25] reveal a fracture process that absorbs more elastic energy when compared to the mirror fracture surfaces of neat epoxy. The increase in the new surface area created during crack growth absorbs additional energy and increases fracture toughness.

In all the other sample types investigated other than well bonded microcapsules - neat epoxy, silica microspheres, UF particles, voids, and poorly bonded microcapsules-hackle markings were restricted to a small region near the crack tip. Fracture planes of epoxy containing voids exhibit a plastic zone, 3D zone with hackle markings, and brittle mirror zone consistent with neat epoxy. In the 3D zone however, the presence of voids locally alters the fracture mechanism, causing small regions of mirror fracture surface encircling intersected voids. The resulting reduction in the total area of hackle marks may account for part of the decline in fracture toughness with the inclusion of voids.

\subsection{Discussion}

Although microcapsules do not behave like hard solid particles, similar fracture behavior has been observed in rubber toughened epoxy. Two separate toughening mechanisms have been identified in the literature for ductile, rubber particles: cavitation and microcracking. Embedded rubber particles respond to the imposed triaxial stress field near a crack tip by debonding from the matrix and cavitating $[8,26]$. Microcapsules do not present a behavior analogous to cavitation, though polymer microcapsules ruptured by a propagating crack 


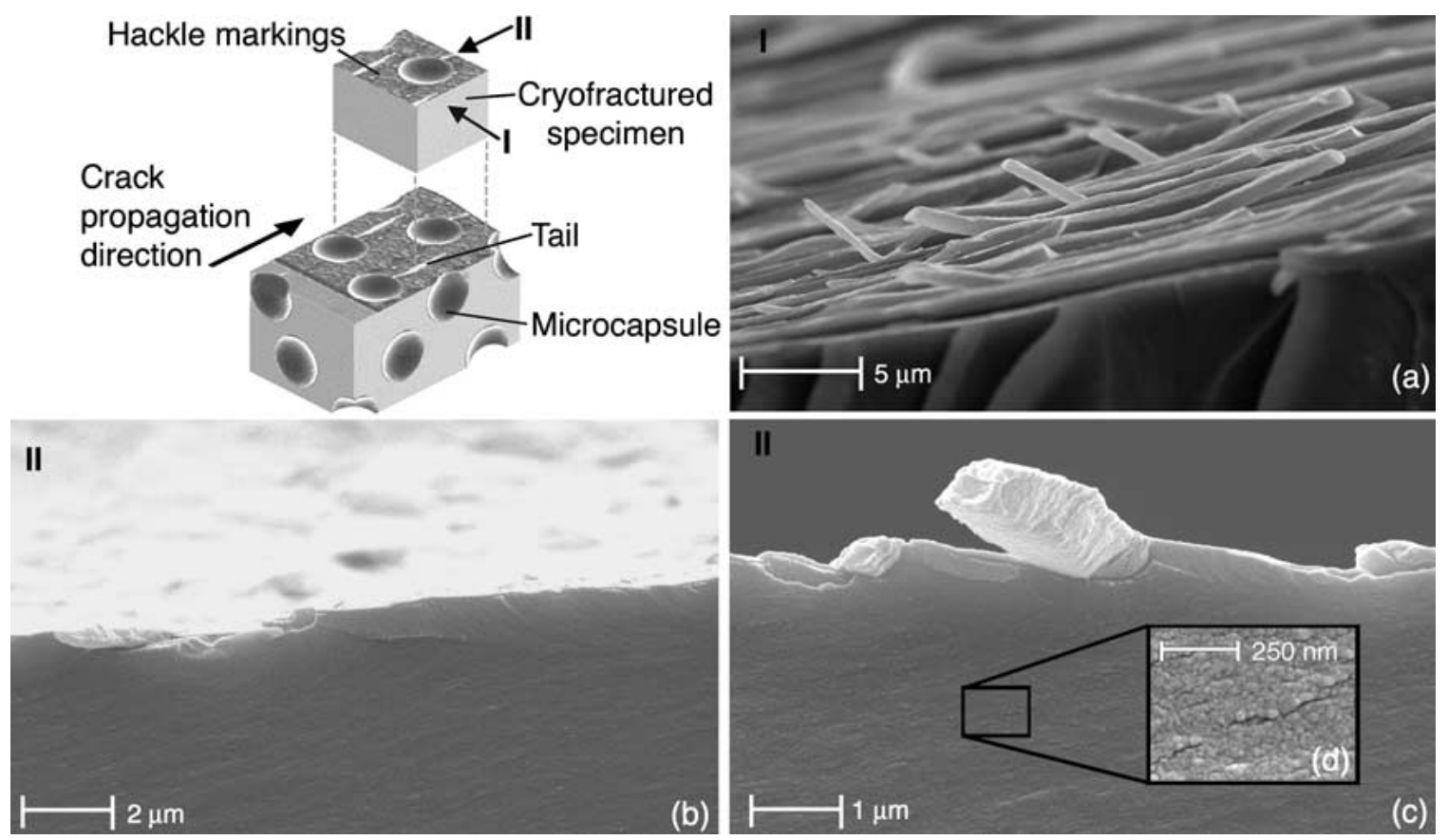

Figure 10 Scanning electron micrographs of cryofractured specimen as viewed from: (a) perpendicular to crack propagation and (b-d) opposite to the direction of crack propagation. Subsurface cracks forming hackle markings are shown in (b) and (c). Microcracks are shown in (d).

have been used to simulate pre-cavitated rubber particles [8]. Rubber particles also act as points of stress concentration under triaxial stress conditions generating shear yielding or microcracking in the matrix [8, 27-29]. The localized deformation and subsurface microcracking associated with rubber toughened epoxy are similar to the mechanisms identified for microcapsule toughened epoxy. The inclusion of 5 to $10 \mathrm{vol} \%$ of rubber particles consistently yields a 50 to $260 \%$ increase of epoxy fracture toughness [4, 8 , 27-29].

\section{Conclusions}

Microcapsule induced toughening was investigated in a self-healing polymer composite. Both the virgin and healed fracture toughness values were strongly dependent on the size and concentration of DCPD-filled UF microcapsules added to the epoxy. Fracture toughness increased with microcapsule concentration until reaching a maximum value. The average maximum toughness was $127 \%$ greater than neat epoxy. The concentration of microcapsules at which the maximum value occurred varied with microcapsule diameter. Samples with smaller microcapsules exhibited maximum toughening at lower concentrations. Moreover, the fracture toughness measured for epoxy with embedded microcapsules was much greater than epoxy samples with similar concentrations of solid silica microspheres or UF polymer particles. Good adhesion between the microcapsules and epoxy matrix was necessary for capsule rupture and any subsequent toughening. The fracture behavior of epoxy with poor microcapsule bonding was identical to samples containing a similar concentration of voids.

Careful examination of the fracture surfaces revealed several of the operative toughening mechanisms. Fracture of the neat epoxy was brittle, exhibiting a mirror fracture surface. The addition of microcapsules produced a transition of the fracture plane morphology to hackle markings. The increased toughening associated with fluid-filled microcapsules was attributed to increased hackle marking and subsurface microcracking not observed for solid particle fillers.

The healed fracture toughness also increased steadily with capsule concentration until reaching a plateau at about $20 \mathrm{vol} \%$. The maximum healing efficiency for $180 \mu \mathrm{m}$ diameter microcapsules occurred at low concentrations ( $\sim 5 \mathrm{vol} \%$ ) just prior to the peak virgin fracture toughness. For $50 \mu \mathrm{m}$ microcapsules, significant healing efficiency was measured only at higher concentrations $(\sim 20 \mathrm{vol} \%)$. Over $70 \%$ recovery of virgin fracture toughness was achieved through careful selection of microcapsule size and concentration.

\section{Acknowledgment}

The authors gratefully acknowledge support from the AFOSR Aerospace and Materials Science Directorate Mechanics and Materials Program under Award No. F49620-00-1-0094 and Motorola Labs, Motorola Advanced Technology Center, Schaumburg Ill. Any opinions, findings, and conclusions or recommendations expressed in this publication are those of the authors and do not necessarily reflect the views of the AFOSR or Motorola Labs. The authors would also like to thank Profs. J. S. Moore, P. V. Braun, and P. H. Geubelle of the Autonomic Materials Laboratory of the Beckman Institute of Advanced Science and Technology and Dr. A. Skipor of Motorola Labs for technical support and helpful discussions. Undergraduate A. Rzeszutko was extremely helpful in preparation and testing of dogbone samples. Electron microscopy was performed in the Imaging Technology Group, Beckman Institute, of the University of Illinois at Urbana-Champaign, with the assistance of S. Robinson. 


\section{References}

1. S. R. White, N. R. Sottos, P. H. Geubelle, J. S. MOORE, M. R. KESSLER, S. R. SRIRAM, E. N. BROWN and S. VIS WANATHAN, Nature 409 (2001) 794.

2. E. L. DIAS, S. T. NGUYEN and R. H. GRUBB S, J. Amer. Chem. Soc. 119 (1997) 3887.

3. E. N. BROWN, N. R. SOTtOS and S. R. WHite, Exp. Mech. 42 (2002) 372.

4. H. R. AZIMI, R. A. PEARSON and R. W. HERTZBERG, Polym. Eng. Sci. 36 (1996) 2352.

5. R. J. CARDOSO, A. SHUKLA and A. BOSE, J. Mater. Sci. 37 (2002) 603.

6. A. M. ZIHlif and G. RAgosta, Polym. Polym. Compos. 9 (2001) 345 .

7. M. A. EL-HADEK and H. V. TIPPUR, J. Mater. Sci.37(2002) 1649.

8. R. BAGHERI and R. A. PEARSON, Polymer 37 (1996) 4529 .

9. H. TODA, H. KAGAJO, K. HOSOI, T. KOBAYASHI, Y. ITO, T. HIGASHIHARA and T. GOHDA, J. Soc. Mater. Sci. Jpn. 50 (2001) 474.

10. H. S. KIM and M. A. KHAMIS, Compos. Part A 32 (2001) 1311.

11. W. H. LIN and M. H. R. JEN, J. Comp. Mater. 32 (1998) 1356.

12. D. JUNG, in "Performance and Properties of Embedded Microspheres for Self-Repairing Applications," MS Thesis, University of Illinois at Urbana-Champaign, 1997, p. 105.

13. S. MOSTOVOY, P. B. CROSLEY and E. J. RIPLING J. Mater. 2 (1967) 661.

14. M. R. KES Sle R and S. R. White, J. Polym. Sci. Part A 40 (2002) 2373.
15. R. P. W OOL and K. M. O'CONNER, J. Appl. Phys. 52 (1981) 5953.

16. J. LEE and A. F. YEE, Polymer 42 (2001) 577

17. E. N. BROWN, M. R. KESSLER, N. R. SOTTOS and S. R. White, J. Microencapsul. 20 (2003) 719.

18. J. SPANOUDAKIS and R. J. YOUNG, J. Mater. Sci. 19 (1984) 487.

19. P. K. MALliCK and L. J. BROUtMAn, Mater. Sci. Eng. 18 (1975) 63.

20. G. R. IRWIN, in Proceedings of the 7th Sagamore Ordnance Materials Research Conference, Vol. 4, Syracuse University, NY (1960) p. 63.

21. A. RABINOVITCH, G. BELIZOVSKY and D. BAHAT, Phys. Rev. B 61 (2000) 14968.

22. A. J. ROSAKIS and K. RAVI-CHANDAR, Int. J. Solids Struct. 22 (1986) 121.

23. F. KER KHOF, Glastech. Ber. 48 (1975) 112.

24. F. F. LANGE, Philos. Mag. 22 (1970) 938.

25. K. RAVI-CHANDAR and W. G. KNAUSS, Int. J. Fract. 26 (1984) 141.

26. L. KONCZOL, W. DOLL, U. BUCHHOLZ and R. Mulhaupt, J. Appl. Polym. Sci. 54 (1994) 815.

27. L. REY, N. POISSON, A. MAAZOUZ and $H$. S A U TEREAU, J. Mater. Sci. 34 (1999) 1775.

28. J. KARGER-KOCSIS and K. FRIEDRICH, Comp. Sci. Technol. 48 (1993) 263.

29. H. R. AZIMI, R. A. PEARSON and R. W. HERTZBERG, J. Mater. Sci. 31 (1996) 3777.

Received 12 March

and accepted 7 October 2003 